\title{
Teorema Titik Tetap Pada Ruang Quasi Metrik Terasing Tanpa Menggunakan Sifat Kekontinuan Fungsi
}

\author{
Malahayati dan Mutia Utami \\ Program Studi Matematika, Fakultas Sains dan Teknologi, UIN Sunan Kalijaga, Jl. Marsda Adisucipto \\ No. 1 Yogyakarta, Indonesia \\ Korespondensi; Malahayati, Email: malahayati_01@yahoo.co.id
}

\begin{abstract}
Abstrak
Ruang kuasi metrik terkompresi adalah ruang dengan fungsi jarak yang hanya memenuhi dua kondisi dari empat kondisi fungsi jarak di ruang metrik. Setiap ruang metrik dislokasi ruang kuasi metrik, namun percakapan tidak memuaskan, sehingga karakter yang memenuhi ruang metrik mungkin tidak terpenuhi dalam ruang metrik kuasi yang terkilir. Makalah ini untuk membaca teorema titik tetap tanpa kontinuitas pemetaan pada ruang kuasi metalik yang terkilir, juga memberi contoh dengan menggunakan teorema yang telah dibacakan.
\end{abstract}

Kata Kunci: Ruang quasi metrik; Titik tetap; Metrik; Ruang metrik

\begin{abstract}
Dislocated quasi metric spaces is spaces with distance function that only satisfies two conditions from four conditions of distance function in metric spaces. Every metric spaces is dislocated quasi metric spaces, but the convers not satifies, so the characters that satisfies in metric spaces may not satisfies in dislocated quasi metric spaces. This paper is to recite fixed point theorems without continuity of any mapping in dislocated quasi metric spaces, also gives an example using the theorems that has recited.
\end{abstract}

Keywords: Dislocated quasi metric spaces; Fixed point; Metric; Metric space

\section{Pendahuluan}

Teorema titik tetap Banach telah menarik banyak peneliti untuk terlibat dalam mempelajari dan mengeksplorasi teorema tersebut untuk mendapatkan hasil yang baru dalam pemetaan kontraksi menggunakan berbagai kondisi. Kannan seorang peneliti yang menggunakan tipe baru pada pemetaan kontraksi namun bersifat tidak kontinu, sedangkan Das, Gupta, dan Ciric memberikan generalisasi prinsip kontraksi Banach pada ruang metrik. Rohades juga telah sukses dalam upaya membangun urutan parsial untuk berbagai definisi pemetaan kontraksi. Hitzler dan Seda mengeluarkan gagasan tentang ruang metrik terasing (dislocated metric spaces) sehingga mampu memperluas prinsip kontraksi Banach di ruang metrik. Selanjutnya Zeyada dan kawan-kawan mengeneralisasikan hasil karya Hitzler dan Seda pada ruang quasi metrik terasing (dislocated quasi metric spaces). Kemudian Aage dan Salunke mempelajari tentang pemetaan yang disampaikan oleh Kannan dan Ciric serta menjelaskan tentang teorema titik tetap pada ruang quasi metrik terasing. Oleh karena itu, Isufati kemudian membuktikan beberapa teorema titik tetap untuk pemetaan kontraksi dan kontinu di ruang quasi metrik terasing yang didefinisikan oleh Das, Gupta dan Rohades.

Pada tahun 2013, Sharma dan Thakur membuktikan teorema titik tetap dengan kondisi pemetaan kontraksi yang sama dengan penelitian yang dilakukan Isufati (2010) di ruang quasi metrik terasing, namun tidak menggunakan sifat kekontinuan fungsi.

Mengkaji dan membahas penelitian yang dilakukan oleh Sharma dan Thakur pada jurnal dengan judul Fixed Point Theorems without Continuity of any Mappings in Dislocated Quasi Metric Space dianggap perlu dan penting, karena merupakan penelitian yang baru dan berbeda dari penelitian sebelumnya, serta dalam jurnal tersebut pembahasan tentang ruang quasi metrik terasing dan 
pembuktian teorema titik tetap tanpa menggunakan sifat kekontinuan fungsi dirasa masih sangat singkat, dan tidak disertai dengan adanya contoh.

Diharapkan dengan membahas dan mengkaji penelitian yang dilakukan oleh Sharma dan Thakur (2013) penulis dapat menjelaskan secara rinci tentang ruang quasi metrik terasing dan pembuktian teorema titik tetap didalamnya tanpa menggunakan sifat kekontinuan fungsi dan diakhiri dengan diberikan suatu contoh sebagai gambaran bagi pembaca.

\section{Landasan Teori}

Pada bagian ini akan diberikan pengertian ruang quasi metrik terasing dan sifat-sifat ruang quasi metrik terasing. Sifat-sifat yang diberikan akan digunakan untuk mempermudah pembahasan selanjutnya.

\section{Pengertian Ruang Quasi Metrik Terasing}

Berikut akan diberikan definisi dan contoh ruang quasi metrik terasing, serta hubungan antara ruang metrik dengan ruang quasi metrik terasing.

Definisi 1.1. (Zeyada, dkk, 2006:111) Diberikan himpunan tidak kosong $X$. Pemetaan $d: X \times X \rightarrow$ $[0, \infty)$ yang memenuhi kondisi:

(1) Jika $d(x, y)=d(y, x)=0$ maka $x=y$, untuk setiap $x, y \in X$ dan

(2) $d(x, y) \leq d(x, z)+d(z, y)$, untuk setiap $x, y, z \in X$

Disebut quasi metrik terasing (disingkat: metrik-dq). Selanjutnya pasangan $(X, d)$ disebut ruang quasi metrik terasing (disingkat: ruang metrik-dq)

Contoh 1.2. Diberikan himpunan $X=\{x, y, z\}$. Jika fungsi $d: X \times X \rightarrow[0, \infty)$ didefinisikan dengan:

$$
\begin{gathered}
d(x, y)=d(z, x)=d(z, y)=\frac{1}{8} \\
d(y, x)=d(x, z)=d(y, z)=\frac{1}{6} \\
d(x, x)=\frac{1}{7}, d(y, y)=0, d(z, z)=\frac{1}{4}
\end{gathered}
$$

Untuk $x, y, z \in X$, maka fungsi $d$ adalah metrik-dq.

Bukti: Ambil sebarang $a, b, c \in X$.

(1) Akan dibuktikan bahwa jika $d(a, b)=d(b, a)=0$, maka $a=b$.

Diketahui bahwa $d(a, b)=0$, berarti $d(a, b)=d(y, y)$ dengan kata lain

$$
a=b=y
$$

Selanjutnya diketahui bahwa $d(b, a)=0$ berarti $d(b, a)=d(y, y)$ dengan kata lain

$$
a=b=y
$$

Karena $d(a, b)=d(b, a)=0$ dan berdasarkan (1) dan (2), maka diperoleh bahwa $a=b$.

(2) Selanjutnya akan dibuktikan bahwa $d(a, b) \leq d(a, c)+d(c, b)$. Terdapat enam kemungkinan yang harus dipenuhi untuk membuktikan kondisi tersebut.

- Apabila memehuni kondisi berikut:

$$
d(a, b)=x(x, y)=\frac{1}{8}
$$




$$
\begin{aligned}
& d(a, c)=x(x, z)=\frac{1}{6} \\
& d(c, b)=x(z, y)=\frac{1}{8}
\end{aligned}
$$

Maka diperoleh:

$$
\frac{1}{8}=x(a, b) \leq d(a, c)+d(c, b)=\frac{1}{6}+\frac{1}{8}=\frac{7}{24}
$$

- Apabila memenuhi kondisi berikut:

$$
\begin{aligned}
& d(a, b)=d(y, x)=\frac{1}{6} \\
& d(a, c)=d(y, z)=\frac{1}{6} \\
& d(c, b)=d(z, x)=\frac{1}{8}
\end{aligned}
$$

Maka diperoleh:

$$
\frac{1}{6}=d(a, b) \leq d(a, c)+d(c, b)=\frac{1}{6}+\frac{1}{8}=\frac{7}{24}
$$

- Apabila memenuhi kondisi berikut:

$$
\begin{aligned}
& d(a, b)=d(z, x)=\frac{1}{8} \\
& d(a, c)=d(z, y)=\frac{1}{8} \\
& d(c, b)=d(y, x)=\frac{1}{6}
\end{aligned}
$$

Maka diperoleh:

$$
\frac{1}{8}=d(a, b) \leq d(a, c)+d(c, b)=\frac{1}{8}+\frac{1}{6}=\frac{7}{24}
$$

- Apabila memenuhi kondisi berikut:

$$
\begin{aligned}
& d(a, b)=d(z, y)=\frac{1}{8} \\
& d(a, c)=d(z, x)=\frac{1}{8} \\
& d(c, b)=d(x, y)=\frac{1}{8}
\end{aligned}
$$


Maka diperoleh:

$$
\frac{1}{8}=d(a, b) \leq d(a, c)+d(c, b)=\frac{1}{8}+\frac{1}{8}=\frac{2}{8}
$$

- Apabila memenuhi kondisi berikut:

$$
\begin{aligned}
& d(a, b)=d(x, y)=\frac{1}{6} \\
& d(a, c)=d(x, y)=\frac{1}{8} \\
& d(c, b)=d(y, z)=\frac{1}{6}
\end{aligned}
$$

Maka diperoleh:

$$
\frac{1}{6}=d(a, b) \leq d(a, c)+d(c, b)=\frac{1}{8}+\frac{1}{6}=\frac{7}{24}
$$

- Apabila memenuhi kondisi berikut:

$$
\begin{aligned}
& d(a, b)=d(y, z)=\frac{1}{6} \\
& d(a, c)=d(y, x)=\frac{1}{6} \\
& d(c, b)=d(x, z)=\frac{1}{6}
\end{aligned}
$$

Maka diperoleh:

$$
\frac{1}{6}=d(a, b) \leq d(a, c)+d(c, b)=\frac{1}{6}+\frac{1}{6}=\frac{2}{6}
$$

Karena keenam kemungkinan terpenuhi, maka terbukti bahwa $d(a, b) \leq d(a, c)+d(c, b)$ untuk setiap $a, b, c \in X$. Karena $d$ memenuhi kedua kondisi metrik-dq, maka $d$ adalah metrik-dq pada himpunan $X$, lebih lanjut pasangan $(X, d)$ merupakan ruang metrik-dq.

Berdasarkan definisi ruang metrik-dq dapat ditarik suatu hubungan yang menyatakan bahwa setiap ruang metrik merupakan ruang metrik-dq namun tidak berlaku sebaliknya, pernyataan tersebut disajikan dalam lemma berikut ini.

Lemma 1.3. Setiap ruang metrik adalah ruang metrik-dq.

Contoh 1.4. Diberikan himpunan tak kosong $X=[0,1]$ dan pemetaan $d: X \times X \rightarrow[0, \infty)$ yang didefinisikan dengan: $d(x, y)=|x-y|+|x|$ untuk setiap $x, y \in X$. Pasangan $(X, d)$ merupakan ruang metrik-dq, tetapi bukan merupakan ruang metrik.

Bukti: Sebelum membuktikan bahwa pasangan $(X, d)$ bukan merupakan ruang metrik akan dibuktikan terlebih dahulu bahwa $(X, d)$ merupakan ruang metrik-dq. Ambil sebarang $x, y, z \in X$.

i. Akan dibuktikan bahwa jika $d(x, y)=d(y, x)=0$ maka $x=y$. 
Diketahui bahwa $d(x, y)=d(y, x)$, berarti $|x-y|+|x|=|y-x|+|y|=0$.

Berdasarkan sifat nilai mutlak diperoleh bahwa:

$$
\begin{aligned}
& |x-y|+|x|=0 \Leftrightarrow|x-y|=0 \wedge|x|=0 \Leftrightarrow x=y \wedge x=0 \\
& |y-x|+|y|=0 \Leftrightarrow|y-x|=0 \wedge|y|=0 \Leftrightarrow y=x \wedge y=0
\end{aligned}
$$

Berdasarkan (3) dan (4) maka diperoleh bahwa $x=y$.

ii. Akan dibuktikan bahwa $d(x, y) \leq d(x, z)+d(z, y)$.

Menggunakan sifat ketaksamaan segitiga diperoleh:

$$
\begin{aligned}
d(x, y) & =|x-y|+|x| \\
& =|x-z+z-y|+|x| \\
& \leq|x-z|+|z-y|+|x| \\
& \leq|x-z|+|z-y|+|x|+|z| \\
& =|x-z|+|x|+|z-y|+|z| \\
& =d(x, z)+d(z, y)
\end{aligned}
$$

Karena $d$ memenuhi kedua kondisi metrik-dq, maka $d$ merupakan metrik-dq pada himpunan $X$, lebih lanjut pasangan $(X, d)$ merupakan ruang metrik-dq.

Selanjutnya akan dibuktikan bahwa pasangan $(X, d)$ bukan merupakan ruang metrik. Fungsi $d$ bukan merupakan metrik pada himpunan $X$, karena terdapat $1 \in X$ tetapi $d(1,1)=|1-1|+|1|=$ $1 \neq 0$, dengan kata lain fungsi $d$ tidak memenuhi kondisi metrik. Jadi pasangan $(X, d)$ bukan merupakan ruang metrik.

Berdasarkan uraian definisi ruang metrik-dq dan hubungan antara ruang metrik dengan ruang metrikdq dapat disimpulkan bahwa sifat-sifat yang berlaku pada ruang metrik belum tentu berlaku pada ruang metrik-dq.

\section{Sifat-sifat Ruang Quasi Metrik Terasing}

Berikut akan diberikan definisi barisan konvergen, barisan Cauchy, dan fungsi kontraksi. Serta beberapa teorema yang melekat pada barisan konvergen dan barisan Cauchy di ruang metrik-dq.

Definisi 2.1. (Zeyada, dkk, 2006: 112) Diberikan ruang metrik-dq $(X, d)$ dan barisan $\left\{x_{n}\right\} \subseteq X$. Barisan $\left\{x_{n}\right\}$ dikatakan konvergen di ruang metrik-dq (disingkat: konvergen-dq) ke $x \in X$ apabila $\lim _{n \rightarrow \infty} d\left(x_{n}, x\right)=\lim _{n \rightarrow \infty} d\left(x, x_{n}\right)=0$.

Selanjutanya barisan $\left\{x_{n}\right\}$ yang konvergen-dq ke $x$ dapat dinotasikan $x_{n} \rightarrow x$. Dalam hal ini $x$ disebut sebagai limit barisan di ruang metrik-dq (disingkat: limit-dq)

Contoh 2.2. Diberikan himpunan tak kosong $X=[0,1]$ dan ruang metrik-dq $(X, d)$ dengan definisi pemetaan $d: X \times X \rightarrow[0, \infty)$ yaitu:

$$
d(x, y)=|x-y|+|x|
$$

Untuk setiap $x, y \in X$. Jika barisan $\left\{x_{n}\right\} \subset X$ didefinisikan dengan: 


$$
x_{n}=\frac{n}{n^{2}+1}
$$

Untuk setiap $n \in \mathbb{N}$, maka barisan $\left\{x_{n}\right\}$ konvergen-dq ke $0 \in \mathbb{R}$

Bukti: Akan dibuktikan barisan $\left\{x_{n}\right\}$ konvergen-dq ke $0 \in \mathbb{R}$ dengan kata lain akan ditunjukkan bahwa $\lim _{n \rightarrow \infty} d\left(x_{n}, 0\right)=\lim _{n \rightarrow \infty} d\left(0, x_{n}\right)=0$. Berdasarkan (5) dan (6) diperoleh:

$$
\begin{aligned}
\lim _{n \rightarrow \infty} d\left(x_{n}, 0\right) & =\lim _{n \rightarrow \infty}\left|x_{n}-0\right|+\left|x_{n}\right| \\
& =\lim _{n \rightarrow \infty}\left|x_{n}\right|+\left|x_{n}\right|=\lim _{n \rightarrow \infty} 2\left|x_{n}\right| \\
& =\lim _{n \rightarrow \infty} 2\left|\frac{n}{n^{2}+1}\right| \\
& =\lim _{n \rightarrow \infty} 2\left(\frac{n}{n^{2}+1}\right) \\
& =0
\end{aligned}
$$

Dan

$$
\begin{aligned}
\lim _{n \rightarrow \infty} d\left(0, x_{n}\right) & =\lim _{n \rightarrow \infty}\left|0-x_{n}\right|+\left|x_{n}\right| \\
& =\lim _{n \rightarrow \infty}\left|-x_{n}\right|+\left|x_{n}\right|=\lim _{n \rightarrow \infty}\left|x_{n}\right|+\left|x_{n}\right|=\lim _{n \rightarrow \infty} 2\left|x_{n}\right| \\
& =\lim _{n \rightarrow \infty} 2\left|\frac{n}{n^{2}+1}\right| \\
& =\lim _{n \rightarrow \infty} 2\left(\frac{n}{n^{2}+1}\right) \\
& =0
\end{aligned}
$$

Berdasarkan (7) dan (8) diperoleh bahwa $\lim _{n \rightarrow \infty} d\left(x_{n}, 0\right)=\lim _{n \rightarrow \infty} d\left(0, x_{n}\right)=0$. Jadi terbutkti bahwa barisan $\left\{x_{n}\right\}$ konvergen-dq ke $0 \in \mathbb{R}$.

Definisi 2.3. (Zeyada, dkk, 2006: 112) Diberikan ruang metrik-dq $(X, d)$ dan barisan $\left\{x_{n}\right\} \subseteq X$. Barisan $\left\{x_{n}\right\}$ dikatakan Cauchy apabila setiap $\varepsilon>0$ terdapat $n_{0} \in \mathbb{N}$ sehingga untuk setiap $m, n \geq n_{0}$ berlaku $d\left(x_{m}, x_{n}\right)<\varepsilon$ atau $d\left(x_{n}, x_{m}\right)<\varepsilon$.

Contoh 2.4. Diberikan himpunan tak kosong $X=[0,1]$ dan ruang metrik-dq $(X, d)$ dengan definisi pemetaan $d: X \times X \rightarrow[0, \infty)$ yaitu:

$$
d(x, y)=|x-y|+|x|
$$

Untuk setiap $x, y \in X$. Jika barisan $\left\{x_{n}\right\} \subset X$ didefinisikan dengan:

$$
x_{n}=\frac{1}{n}
$$


Untuk setiap $n \in \mathbb{N}$, maka barisan $\left\{x_{n}\right\}$ adalah barisan Cauchy.

Bukti: Ambil sebarang $\varepsilon>0$, berdasarkan hukum Archimedes maka terdapat $n_{0} \in \mathbb{N}$ sedemikian sehingga $\frac{1}{n_{0}}<\frac{\varepsilon}{2}$. Oleh karena itu untuk setiap $n, m \geq n_{0}$ dengan asumsi $m>n$ diperoleh:

$$
\begin{aligned}
d\left(x_{n}, x_{m}\right) & =\left|x_{n}-x_{m}\right|+\left|x_{n}\right| \\
& =\left|\frac{1}{n}-\frac{1}{m}\right|+\left|\frac{1}{n}\right|=\left|\frac{m-n}{n m}\right|+\left|\frac{1}{n}\right| \\
& =\frac{m-n}{n m}+\frac{1}{n} \\
& <\frac{m}{n m}+\frac{1}{n}=\frac{2}{n} \leq 2 \frac{1}{n_{0}}<2 \frac{\varepsilon}{2}=\varepsilon
\end{aligned}
$$

Jadi terbukti bahwa $\left\{x_{n}\right\}$ adalah barisan Cauchy.

Berikut ini akan diberikan definisi ruang metrik-dq lengkap.

Definisi 2.5. (Zeyada, dkk, 2006: 112) Ruang metrik-dq dikatakan lengkap apabila setiap barisan Cauchy di dalamnya konvergen-dq.

Contoh 2.6. Diberikan himpunan tak kosong $X=[0,1] \subset \mathbb{R}$ dan pemetaan $d: X \times X \rightarrow[0, \infty)$ yang didefinisikan dengan:

$$
d(x, y)=|x-y|+|x|
$$

Untuk setiap $x, y \in X$, pasangan $(X, d)$ merupakan ruang metrik-dq lengkap.

Bukti: Telah dibuktikan sebelumnya pada Contoh 2.4 bahwa pasangan $(X, d)$ merupakan ruang metrik-dq. Selanjutnya akan dibuktikan bahwa pasangan $(X, d)$ merupakan ruang metrik-dq lengkap.

Ambil sebarang barisan Cauchy $\left\{x_{n}\right\} \subset X$. Karena $\left\{x_{n}\right\}$ adalah barisan Cauchy berarti untuk setiap $\varepsilon>0$ dan $n_{0} \in \mathbb{N}$ sehingga untuk setiap $n, m \geq n_{0}$ berlaku:

$$
\begin{gathered}
d\left(x_{n}, x_{m}\right)<\varepsilon \\
\Leftrightarrow\left|x_{n}-x_{m}\right|+\left|x_{n}\right|<\varepsilon
\end{gathered}
$$

Karena $\left|x_{n}-x_{m}\right|+\left|x_{n}\right|<\varepsilon$ maka $\left|x_{n}-x_{m}\right|<\varepsilon$ dengan kata lain $\left\{x_{n}\right\}$ merupakan barisan Cauchy di $\mathbb{R}$. Karena $\mathbb{R}$ mempunyai sifat lengkap maka barisan $\left\{x_{n}\right\}$ konvergen, misalkan barisan $\left\{x_{n}\right\}$ konvergen ke $x$. Jelas $x \in X$, karena barisan $\left\{x_{n}\right\} \subset X$ dan $X$ merupakan himpunan tertutup.

Selanjutnya akan ditunjukan bahwa barisan $\left\{x_{n}\right\}$ konvergen-dq $x \in X$, dengan kata lain akan ditunjukkan bahwa $\lim _{n \rightarrow \infty} d\left(x_{n}, x\right)=\lim _{n \rightarrow \infty} d\left(x, x_{n}\right)=0$.

Berdasarkan (9) dan karena $\left\{x_{n}\right\} \subset X$ merupakan barisan Cauchy, maka diperoleh bahwa:

$$
\begin{aligned}
\lim _{n \rightarrow \infty} d\left(x_{n}, x\right) & =\lim _{n \rightarrow \infty}\left|x_{n}-x\right|+\left|x_{n}\right| \\
& =\lim _{n \rightarrow \infty}\left|x_{n}-\lim _{n \rightarrow \infty} x_{m}\right|+\left|x_{n}\right|
\end{aligned}
$$




$$
\begin{aligned}
& =\lim _{n \rightarrow \infty}\left|x_{n}-x_{m}\right|+\left|x_{n}\right| \\
& =\lim _{n \rightarrow \infty} d\left(x_{n}, x_{m}\right) \\
& =0
\end{aligned}
$$

Dan

$$
\begin{aligned}
\lim _{n \rightarrow \infty} d\left(x, x_{n}\right) & =\lim _{n \rightarrow \infty}\left|x-x_{n}\right|+\left|x_{n}\right| \\
& =\lim _{n \rightarrow \infty}\left|\lim _{n \rightarrow \infty} x_{m}-x_{n}\right|+\lim _{n \rightarrow \infty}\left|x_{m}\right| \\
& =\lim _{n \rightarrow \infty}\left|x_{m}-x_{n}\right|+\left|x_{m}\right| \\
& =\lim _{n \rightarrow \infty} d\left(x_{m}, x_{n}\right) \\
& =0
\end{aligned}
$$

Berdasarkan (10) dan (11) diperoleh $\lim _{n \rightarrow \infty} d\left(x_{n}, x\right)=\lim _{n \rightarrow \infty} d\left(x, x_{n}\right)=0$, dengan kata lain berisan $\left\{x_{n}\right\}$ konvergen-dq ke $x \in X$. Jadi terbukti bahwa $(X, d)$ adalah ruang metrik-dq lengkap.

Sebelumnya telah diketahui bahwa nilai limit barisan pada ruang metrik tunggal, hal ini berlaku pula di ruang metrik-dq yang akan disajikan pada lemma berikut ini.

Lemma 2.7. (Sharma dan Thakur, 2013: 60) Limit barisan di ruang metrik-dq bernilai tunggal.

Bukti: Ambil sebarang ruang metrik-dq $(X, d)$, dan barisan konvergen-dq $\left\{x_{n}\right\} \subseteq X$. Misalkan barisan $\left\{x_{n}\right\}$ konvergen-dq ke $x$ dan $y$. Selanjutnya akan didefinisikan bahwa $x=y$. Karena barisan $\left\{x_{n}\right\}$ konvergen-dq ke $x$ dan $y$, maka berdasarkan Definisi 2.1 berarti:

$$
\begin{aligned}
& \lim _{n \rightarrow \infty} d\left(x_{n}, x\right)=\lim _{n \rightarrow \infty} d\left(x, x_{n}\right)=0 \\
& \lim _{n \rightarrow \infty} d\left(x_{n}, y\right)=\lim _{n \rightarrow \infty} d\left(y, x_{n}\right)=0
\end{aligned}
$$

Berdasarkan Definisi 1.1 (2) perhatikan bahwa:

$$
d(x, y) \leq d\left(x, x_{n}\right)+d\left(x_{n}, y\right)
$$

Dengan demikian maka:

$$
\lim _{n \rightarrow \infty} d(x, y) \leq \lim _{n \rightarrow \infty} d\left(x, x_{n}\right)+\lim _{n \rightarrow \infty} d\left(x_{n}, y\right)
$$

Oleh karena itu berdasarkan (12) dan (13) maka diperoleh $d(x, y)=0$.

Selanjutnya berdasarkan Definisi 1.1 (2) perhatikan bahwa:

$$
d(y, x) \leq d\left(y, x_{n}\right)+d\left(x_{n}, x\right)
$$

Dengan demikian maka: 


$$
\lim _{n \rightarrow \infty} d(y, x) \leq \lim _{n \rightarrow \infty} d\left(y, x_{n}\right)+\lim _{n \rightarrow \infty} d\left(x_{n}, x\right)
$$

Oleh karena itu berdasarkan (12) dan (13) maka diperoleh $d(y, x)=0$.

Karena diperoleh $d(x, y)=d(y, x)=0$, maka berdasarkan Definisi 2.1 (i) diperoleh bahwa $x=y$, dengan kata lain terbukti bahwa nilai limit barisan di ruang metrik-dq $(X, d)$ tunggal.

Berikut ini akan diberikan definisi fungsi kontraksi pada ruang metrik-dq.

Definisi 2.8. (Sharma dan Thakur, 2013: 61) Diberikan ruang metrik-dq $(X, d)$. Pemetaan $f: X \rightarrow X$ dikatakan kontraksi (constraction) apabila terdapat $0 \leq \lambda<1$ sehingga:

Untuk setiap $x, y \in X$

$$
d(f(x), f(y)) \leq \lambda d(x, y)
$$

Contoh 2.9. Diberikan himpunan tak kosong $X=[0,1]$ dan ruang metrik-dq $(X, d)$ yang didefinisikan dengan:

$$
d(x, y)=|x-y|+|x|
$$

Untuk setiap $x, y \in X$. Jika pemetaan $f: X \rightarrow X$ didefinisikan dengan:

$$
f(x)=\frac{x}{2}
$$

Untuk setiap $x \in X$, maka pemetaan $f$ kontraksi.

Bukti: Ambil sebarang $x, y \in X$, berdasarkan (14) dan (15) diperoleh:

$$
\begin{aligned}
d(f(x), f(y)) & =\left|\frac{x}{2}-\frac{y}{2}\right|+\left|\frac{x}{2}\right| \\
& =\left|\frac{1}{2}(x-y)\right|+\left|\frac{1}{2} x\right| \\
& =\left|\frac{1}{2}\right||x-y|+\left|\frac{1}{2}\right||x| \\
& =\left|\frac{1}{2}\right|(|x-y|+|x|) \\
& =\frac{1}{2} d(x, y)
\end{aligned}
$$

Sehingga diperoleh $\lambda=\frac{1}{2}$. Karena $\lambda<1$ maka terbukti bahwa pemetaan $f$ kontraksi.

\section{Pembahasan}

Setelah pengertian ruang metrik-dq dan sifat-sifat pada ruang metrik-dq diberikan, selanjutnya akan dibahas teorema titik tetap pada ruang metrik-dq.

\section{Teorema Titik Tetap Pada Ruang Quasi Metrik Terasing}

Berikut ini akan dibahas dua teorema titik tetap pada ruang metrik-dq tanpa menggunakan sifat kekontinuan fungsi dan diakhiri dengan diberikan suatu contoh. 
Teorema 3.1.1. (Sharma dan Thakur, 2013: 61) Diberikan ruang metrik-dq lengkap $(X, d)$. jika diberikan pemetaan $f: X \rightarrow X$ dan dipenuhi kondisi berikut:

$$
d(f(x), f(y)) \leq \alpha \frac{d(y, f(y))[1+d(x, f(x))]}{(1+d(x, y))}+\beta d(x, y)
$$

Untuk setiap $x, y \in X$ dan $\alpha, \beta>0$ dengan $\alpha+\beta<1$, maka pemetaan $f$ mempunyai titik tetap tunggal.

Bukti: Ambil sebarang barisan $\left\{x_{n}\right\} \subseteq X$ dan $x_{0} \in X$. Kemudian didefinisikan:

$$
\begin{gathered}
f\left(x_{0}\right)=x_{1} \\
f\left(x_{1}\right)=x_{2} \\
f\left(x_{2}\right)=x_{3} \\
\vdots \\
f\left(x_{n}\right)=x_{n+1}
\end{gathered}
$$

Berdasarkan (16) perhatikan bahwa:

$$
\begin{aligned}
d\left(x_{n}, x_{n+1}\right) & =d\left(f\left(x_{n-1}\right), f\left(x_{n}\right)\right) \\
& \leq \frac{\alpha d\left(x_{n}, f\left(x_{n}\right)\right)\left[1+d\left(x_{n-1}, f\left(x_{n-1}\right)\right)\right]}{\left[1+d\left(x_{n-1}, x_{n}\right)\right]}+\beta d\left(x_{n-1}, x_{n}\right) \\
& =\frac{\alpha d\left(x_{n}, x_{n+1}\right)\left[1+d\left(x_{n-1}, x_{n}\right)\right]}{\left[1+d\left(x_{n-1}, x_{n}\right)\right]}+\beta d\left(x_{n-1}, x_{n}\right) \\
& =\alpha d\left(x_{n}, x_{n+1}\right)+\beta d\left(x_{n-1}, x_{n}\right)
\end{aligned}
$$

Dengan demikian diperoleh:

$$
\begin{aligned}
& d\left(x_{n}, x_{n+1}\right) \leq \alpha d\left(x_{n}, x_{n+1}\right)+\beta d\left(x_{n-1}, x_{n}\right) \\
\Leftrightarrow & -\alpha d\left(x_{n}, x_{n+1}\right)+d\left(x_{n}, x_{n+1}\right) \leq-\alpha d\left(x_{n}, x_{n+1}\right)+\alpha d\left(x_{n}, x_{n+1}\right)+\beta d\left(x_{n-1}, x_{n}\right) \\
\Leftrightarrow & (1-\alpha) d\left(x_{n}, x_{n+1}\right) \leq \beta d\left(x_{n-1}, x_{n}\right) \\
\Leftrightarrow & d\left(x_{n}, x_{n+1}\right) \leq \frac{\beta}{(1-\alpha)} d\left(x_{n-1}, x_{n}\right)
\end{aligned}
$$

Apabila $\lambda=\frac{\beta}{(1-\alpha)}$ dengan $0 \leq \lambda<1$ maka diperoleh $d\left(x_{n}, x_{n+1}\right) \leq \lambda d\left(x_{n-1}, x_{n}\right)$

Dengan cara yang sama apabila proses ini dilakukan untuk setiap $n \in \mathbb{N}$, maka:

Untuk $n=1$ diperoleh:

$$
d\left(x_{1}, x_{2}\right) \leq \lambda d\left(x_{0}, x_{1}\right)
$$

Selanjutnya berdasarkan (17) maka untuk $n=2$, diperoleh: 


$$
\begin{aligned}
d\left(x_{2}, x_{3}\right) & \leq \lambda d\left(x_{1}, x_{2}\right) \\
& \leq \lambda\left\{\lambda d\left(x_{0}, x_{1}\right)\right\} \\
& =\lambda^{2} d\left(x_{0}, x_{1}\right)
\end{aligned}
$$

Berdasarkan (18) selanjutnya untuk $n=3$, diperoleh:

$$
\begin{aligned}
d\left(x_{3}, x_{4}\right) & \leq \lambda d\left(x_{2}, x_{3}\right) \\
& \leq \lambda\left\{\lambda^{2} d\left(x_{0}, x_{1}\right)\right\} \\
& =\lambda^{3} d\left(x_{0}, x_{1}\right)
\end{aligned}
$$

Lebih lanjut untuk setiap $n \in \mathbb{N}$, maka diperoleh:

$$
d\left(x_{n}, x_{n+1}\right) \leq \lambda^{n} d\left(x_{0}, x_{1}\right)
$$

Berdasarkan (20) apabila $n \rightarrow \infty$ maka $\lambda^{n} \rightarrow 0$ karena $0 \leq \lambda<1$. Oleh karena itu $d\left(x_{n}, x_{n+1}\right) \rightarrow 0$ untuk $n \rightarrow \infty$. Dengan kata lain $\left\{x_{n}\right\}$ adalah barisan Cauchy di $X$.

Selanjutnya karena $X$ adalah ruang metrik-dq lengkap maka berdasarkan Definisi 2.5 barisan $\left\{x_{n}\right\}$ konvergen-dq. Misalkan barisan $\left\{x_{n}\right\}$ konvergen-dq ke $z \in X$, sehingga berdasarkan (3.1) diperoleh:

$$
\begin{aligned}
d\left(x_{n+1}, x_{n+1}\right) & =d\left(f\left(x_{n}\right), f\left(x_{n}\right)\right) \\
& \leq \frac{\alpha d\left(x_{n}, f\left(x_{n}\right)\right)\left[1+d\left(x_{n}, f\left(x_{n}\right)\right)\right]}{\left[1+d\left(x_{n}, x_{n}\right)\right]}+\beta d\left(x_{n}, x_{n}\right) \\
& =\frac{\alpha d\left(x_{n}, x_{n+1}\right)\left[1+d\left(x_{n}, x_{n+1}\right)\right]}{\left[1+d\left(x_{n}, x_{n}\right)\right]}+\beta d\left(x_{n}, x_{n}\right)
\end{aligned}
$$

Dengan demikian:

$$
\begin{aligned}
& \lim _{n \rightarrow \infty} d\left(x_{n+1}, x_{n+1}\right) \leq \lim _{n \rightarrow \infty}\left[\frac{\alpha d\left(x_{n}, x_{n+1}\right)\left[1+d\left(x_{n}, x_{n+1}\right)\right]}{\left[1+d\left(x_{n}, x_{n}\right)\right]}+\beta d\left(x_{n}, x_{n}\right)\right] \\
\Leftrightarrow & d(z, z) \leq \frac{\alpha d(z, z)[1+d(z, z)]}{[1+d(z, z)]}+\beta d(z, z) \\
\Leftrightarrow & d(z, z) \leq(\alpha+\beta) d(z, z)
\end{aligned}
$$

Hal tersebut tidak mungkin terjadi karena $0 \leq \alpha+\beta<1$ dan $d(z, z) \geq 0$ sehingga yang memenuhi adalah $d(z, z)=0$.

Selanjutnya untuk menunjukkan bahwa $z$ adalah titik tetap pada pemetaan $f$, berdasarkan (17) diperoleh:

$$
d\left(f(z), f\left(x_{n}\right)\right) \leq \frac{\alpha d\left(x_{n}, f\left(x_{n}\right)\right)[1+d(z, f(z))]}{\left[1+d\left(z, x_{n}\right)\right]}+\beta d\left(z, x_{n}\right)
$$

Dengan demikian: 


$$
\begin{aligned}
\lim _{n \rightarrow \infty} d\left(f(z), f\left(x_{n}\right)\right) & \leq \lim _{n \rightarrow \infty}\left[\frac{\alpha d\left(x_{n}, f\left(x_{n}\right)\right)[1+d(z, f(z))]}{\left[1+d\left(z, x_{n}\right)\right]}+\beta d\left(z, x_{n}\right)\right] \\
d(f(z), z) & \leq \frac{\alpha d(z, z)[1+d(z, f(z))]}{[1+d(z, z)]}+\beta d(z, z) \\
& =\frac{\alpha \cdot 0 \cdot[1+d(z, f(z))]}{[1+0]}+\beta .0 \\
d(f(z), z) & \leq 0
\end{aligned}
$$

Hal ini tidak mungkin terjadi sehingga yang memenuhi adalah $d(f(z), z)=0$. Dengan cara yang sama diperoleh juga bahwa $d(z, f(z))=0$. Oleh karena $d(f(z), z)=d(z, f(z))=0$ maka berdasarkan Definisi 1.1 (i) diperoleh $f(z)=z$ dengan kata lain $z$ adalah titik tetap $f$.

Kemudian untuk membuktikan ketunggalan titik tetap pada pemetaan $f$, diberikan $w$ sebagai titik tetap lain pada $f$ dengan $w \neq z$.

Berdasarkan (3.1) maka diperoleh:

$$
\begin{aligned}
& d(z, w)=d(f(z), f(w)) \leq \frac{\alpha d(w, f(w))[1+d(z, f(z))]}{[1+d(z, w)]}+\beta d(z, w) \\
\Leftrightarrow & d(z, w) \leq \frac{\alpha d(w, w)[1+d(z, z)]}{[1+d(z, w)]}+\beta d(z, w) \\
\Leftrightarrow & d(z, w) \leq \beta d(z, w)
\end{aligned}
$$

Hal ini tidak mungkin terjadi, sebab $0 \leq \beta<1$ dan $d(z, w) \geq 0$ sehingga yang memenuhi adalah $d(z, w)=0$. Dengan cara yang sama diperoleh juga bahwa $d(w, z)=0$. Karena $d(z, w)=d(w, z)=$ 0 maka berdasarkan Definisi 1.1 (i) diperoleh $z=w$. Sehingga terbukti bahwa pemetaan $f$ mempunyai titik tetap tunggal.

Berdasarkan Teorema 3.1.1 telah terbukti bahwa tanpa menggunakan sifat kekontinuan fungsi, pemetaan $f$ yang memenuhi kondisi (17) di ruang metrik-dq mempunyai titik tetap yang tunggal. Selain memenuhi kondisi (17) terdapat kondisi lain yang menyebabkan pemetaan $f$ tetap dimiliki titik tetap yang tunggal. Kondisi tersebut akan disajikan pada Teorema 3.1.2 berikut ini.

Teorema 3.1.2 (Sharma dan Thakar, 2013: 62) Diberikan ruang metrik-dq lengkap $(X, d)$. Jika diberikan pemetaan $f: X \rightarrow X$ dan dipenuhi kondisi berikut:

$$
d(f(x), f(y)) \leq \alpha d(x, f(y))+\beta d(y, f(x))+\gamma d(x, y)
$$

Dengan $\alpha, \beta, \gamma$ bernilai non negative dan bergantung pada $x$ dan $y$ yaitu $\sup \{2 \alpha+2 \beta+\gamma: x, y \in$ $X\}<1$, maka pemetaan $f$ mempunyai titik tetap tunggal.

Bukti: Ambil sebarang barisan $\left\{x_{n}\right\} \subseteq X$ dan $x_{0} \in X$. Kemudian didefinisikan:

$$
\begin{gathered}
f\left(x_{0}\right)=x_{1} \\
f\left(x_{1}\right)=x_{2} \\
f\left(x_{2}\right)=x_{3} \\
\vdots \\
f\left(x_{n}\right)=x_{n+1} .
\end{gathered}
$$


Berdasarkan (21) perhatikan bahwa:

$$
\begin{aligned}
d\left(x_{n}, x_{n+1}\right) & =d\left(f\left(x_{n-1}\right), f\left(x_{n}\right)\right) \\
& \leq \alpha d\left(x_{n-1}, f\left(x_{n}\right)\right)+\beta d\left(x_{n}, f\left(x_{n-1}\right)\right)+\gamma d\left(x_{n-1}, x_{n}\right) \\
& =\alpha d\left(x_{n-1}, x_{n+1}\right)+\beta d\left(x_{n}, x_{n}\right)+\gamma d\left(x_{n-1}, x_{n}\right) \\
& \leq \alpha d\left(x_{n-1}, x_{n}\right)+\alpha d\left(x_{n}, x_{n+1}\right)+\beta d\left(x_{n-1}, x_{n}\right)+\beta d\left(x_{n}, x_{n+1}\right)+\gamma d\left(x_{n-1}, x_{n}\right) \\
& =(\alpha+\beta+\gamma) d\left(x_{n-1}, x_{n}\right)+(\alpha+\beta) d\left(x_{n}, x_{n+1}\right)
\end{aligned}
$$

Dengan demikian diperoleh:

$$
\begin{aligned}
& d\left(x_{n}, x_{n+1}\right)-(\alpha+\beta) d\left(x_{n}, x_{n+1}\right) \leq(\alpha+\beta+\gamma) d\left(x_{n-1}, x_{n}\right)-(\alpha+\beta) d\left(x_{n}, x_{n+1}\right) \\
\Leftrightarrow & {[1-(\alpha+\beta)] d\left(x_{n}, x_{n+1}\right) \leq(\alpha+\beta+\gamma) d\left(x_{n-1}, x_{n}\right) } \\
\Leftrightarrow & d\left(x_{n}, x_{n+1}\right) \leq \frac{(\alpha+\beta+\gamma)}{[1-(\alpha+\beta)]} d\left(x_{n-1}, x_{n}\right)
\end{aligned}
$$

Apabila $\lambda=\frac{(\alpha+\beta+\gamma)}{[1-(\alpha+\beta)]}$ dengan $0 \leq \lambda<1$ maka diperoleh:

$$
d \lambda\left(x_{n}, x_{n+1}\right) \leq \lambda d\left(x_{n-1}, x_{n}\right)
$$

Dengan cara yang sama apabila proses ini dilakukan untuk setiap $n \in \mathbb{N}$, maka:

Untuk $n=1$ diperoleh:

$$
d\left(x_{1}, x_{2}\right) \leq \lambda d\left(x_{0}, x_{1}\right)
$$

Selanjutnya berdasarkan (22) maka untuk $n=2$, diperoleh:

$$
\begin{aligned}
d\left(x_{2}, x_{3}\right) & \leq \lambda d\left(x_{1}, x_{2}\right) \\
& \leq \lambda\left\{\lambda d\left(x_{0}, x_{1}\right)\right\} \\
& =\lambda^{2} d\left(x_{0}, x_{1}\right)
\end{aligned}
$$

Berdasarkan (23) selanjutnya untuk $n=3$, diperoleh:

$$
\begin{aligned}
d\left(x_{3}, x_{4}\right) & \leq \lambda d\left(x_{2}, x_{3}\right) \\
& \leq \lambda\left\{\lambda^{2} d\left(x_{0}, x_{1}\right)\right\} \\
& =\lambda^{3} d\left(x_{0}, x_{1}\right)
\end{aligned}
$$

Lebih lanjut untuk setiap $n \in \mathbb{N}$, maka diperoleh:

$$
d\left(x_{n}, x_{n+1}\right) \leq \lambda^{n} d\left(x_{0}, x_{1}\right)
$$

Berdasarkan (25) apabila $n \rightarrow \infty$ maka $\lambda^{n} \rightarrow 0$ karena $0 \leq \lambda<1$. Oleh karena itu $d\left(x_{n}, x_{n+1}\right) \rightarrow 0$ untuk $n \rightarrow \infty$. Dengan kata lain $\left\{x_{n}\right\}$ adalah barisan Cauchy di $X$. Selanjutnya karena $X$ adalah ruang metrik-dq lengkap maka berdasarkan Definisi 2.5 barisan $\left\{x_{n}\right\}$ konvergen-dq. Misalkan barisan $\left\{x_{n}\right\}$ konvergen-dq ke $z \in X$, sehingga berdasarkan (21) diperoleh: 


$$
\begin{aligned}
d\left(x_{n+1}, x_{n+1}\right) & =d\left(f\left(x_{n}\right), f\left(x_{n}\right)\right) \\
& \leq \alpha d\left(x_{n}, f\left(x_{n}\right)\right)+\beta d\left(x_{n}, f\left(x_{n}\right)\right)+\gamma d\left(x_{n}, x_{n}\right) \\
& \leq \alpha d\left(x_{n}, x_{n+1}\right)+\beta d\left(x_{n}, x_{n+1}\right)+\gamma d\left(x_{n}, x_{n}\right)
\end{aligned}
$$

Dengan demikian:

$$
\begin{aligned}
& \lim _{n \rightarrow \infty} d\left(x_{n+1}, x_{n+1}\right) \leq \lim _{n \rightarrow \infty}\left[\alpha d\left(x_{n}, x_{n+1}\right)+\beta d\left(x_{n}, x_{n+1}\right)+\gamma d\left(x_{n}, x_{n}\right)\right] \\
\Leftrightarrow & d(z, z) \leq \alpha d(z, z)+\beta d(z, z)+\gamma d(z, z) \\
\Leftrightarrow & d(z, z) \leq(\alpha+\beta+\gamma) d(z, z)
\end{aligned}
$$

Karena $0 \leq(\alpha+\beta+\gamma)<1$ dan $d(z, z) \geq 0$ sehingga diperoleh bahwa $d(z, z)=0$. Selanjutnya untuk menunjukkan bahwa $z$ adalah titik tetap pada pemetaan $f$, berdasarkan (3.6) diperoleh:

$$
\begin{aligned}
& d\left(f(z), f\left(x_{n}\right)\right) \leq \alpha d\left(z, f\left(x_{n}\right)\right)+\beta d\left(x_{n}, f(z)\right)+\gamma d\left(z, x_{n}\right) \\
\Leftrightarrow & d\left(f(z), x_{n+1}\right) \leq \alpha d\left(z, x_{n+1}\right)+\beta d\left(x_{n}, f(z)\right)+\gamma d\left(z, x_{n}\right)
\end{aligned}
$$

Dengan demikian:

$$
\begin{aligned}
& \lim _{n \rightarrow \infty} d\left(f(z), x_{n+1}\right) \leq \lim _{n \rightarrow \infty}\left[\alpha d\left(z, x_{n+1}\right)+\beta d\left(x_{n}, f(z)\right)+\gamma d\left(z, x_{n}\right)\right] \\
\Leftrightarrow & d(f(z), z) \leq \alpha d(z, z)+\beta d(z, f(z))+\gamma d(z, z) \\
\Leftrightarrow & d(f(z), z) \leq \beta d(z, f(z))
\end{aligned}
$$

Karena $0 \leq \beta<1$ sehingga diperoleh bahwa $d(f(z), z)=0$. Dengan cara yang sama diperoleh juga bahwa $d(z, f(z))=0$. Oleh karena $d(f(z), z)=d(z, f(z))=0$ maka berdasarkan Definisi 1.1 (i) diperoleh $f(z)=z$ dengan kata lain $z$ adalah titik tetap $f$.

Selanjutnya untuk membuktikan ketunggalan titik tetap pada pemetaan $f$, diberikan $w$ sebagai titik tetap lain pada $f$ dengan $w \neq z$.

Berdasarkan (21) maka diperoleh:

$$
\begin{aligned}
d(z, w) & =d(f(z), f(w)) \\
& \leq \alpha d(z, f(w))+\beta d(w, f(z))+\gamma d(z, w) \\
& =\alpha d(z, w)+\beta d(w, z)+\gamma d(z, w) \\
& =(\alpha+\gamma) d(z, w)+\beta d(w, z)
\end{aligned}
$$

dan

$$
\begin{aligned}
d(w, z) & =d(f(w), f(z)) \\
& \leq \alpha d(w, f(z))+\beta d(z, f(w))+\gamma d(w, z) \\
& =\alpha d(w, z)+\beta d(z, w)+\gamma d(w, z) \\
& =(\alpha+\gamma) d(w, z)+\beta d(z, w)
\end{aligned}
$$


Berdasarkan (26) dan (27) diperoleh:

$$
\begin{aligned}
d(z, w)-d(w, z) & \leq(\alpha+\gamma) d(z, w)+\beta d(w, z)-(\alpha+\gamma) d(w, z)-\beta d(z, w) \\
& =(\alpha+\gamma) d(z, w)-\beta d(z, w)-(\alpha+\gamma) d(w, z)+\beta d(w, z) \\
& =[(\alpha+\gamma)-\beta] d(z, w)-[(\alpha+\gamma)-\beta] d(w, z) \\
& =[(\alpha+\gamma)-\beta](d(z, w)-d(w, z))
\end{aligned}
$$

Sehingga:

$$
|d(z, w)-d(w, z)| \leq[(\alpha+\gamma)-\beta]|d(z, w)-d(w, z)|
$$

Karena $0 \leq[(\alpha+\gamma)-\beta]<1$ maka berakibat $d(z, w)-d(w, z)=0$. Oleh karena itu diperoleh bahwa $d(z, w)=d(w, z)$. Berdasarkan (3.11) dan (3.12) karena $d(z, w)=d(w, z)$ maka diperoleh:

$$
d(z, w) \leq(\alpha+\beta+\gamma) d(z, w)
$$

Karena $0 \leq(\alpha+\beta+\gamma)<1$ sehingga diperoleh bahwa $d(w, z)=0$ dan $d(w, z)=0$. Oleh karena $d(z, w)=d(w, z)=0$ maka berdasarkan Definisi 1.1 (i) diperoleh $z=w$. Sehingga terbukti bahwa pemetaan $f$ mempunyai titik tetap tunggal.

Contoh 3.1.3 Diberikan himpunan tak kosong $X=[0,1]$. Didefinisikan fungsi $d: X \times X \rightarrow[0, \infty)$ dengan:

$$
d(x, y)=|x-y|+|x|
$$

Untuk setiap $x, y \in X$. Berdasarkan Contoh 2.6 jelas bahwa pasangan $(X, d)$ merupakan ruang metrikdq lengkap. Jika fungsi $f: X \rightarrow X$ didefinisikan dengan:

$$
f(x)=\frac{x}{8}
$$

Untuk setiap $x \in X$, maka pemetaan $f$ mempunyai titik tetap tunggal.

Bukti: Untuk membuktikan bahwa pemetaan $f$ mempunyai titik tetap tunggal, lihat kembali Teorema 3.1.2. Selanjutnya akan ditunjukkan bahwa pemetaan $f$ memenuhi kondisi (21). Ambil sebarang $x, y \in$ $X$. Berdasarkan (28) dan (29) perhatikan bahwa:

$$
\begin{aligned}
d(f(x), f(y)) & =d\left(\frac{x}{8}, \frac{y}{8}\right) \\
& =\left|\frac{x}{8}-\frac{y}{8}\right|+\left|\frac{x}{8}\right| \\
& =\left|\frac{1}{8}(x-y)\right|+\left|\frac{1}{8}(x)\right| \\
& =\frac{1}{8}|x-y|+\frac{1}{8}|x|
\end{aligned}
$$

Sebelumnya perhatikan bahwa: 


$$
\begin{aligned}
|x-y| & =\left|x-\frac{y}{8}+\frac{y}{8}-y\right| \\
& \leq\left|x-\frac{y}{8}\right|+\left|\frac{y}{8}-y\right| \\
& =\left|x-\frac{y}{8}\right|+\left|\frac{7}{8} y\right| \\
& \leq\left|x-\frac{y}{8}\right|+|y| \\
& \leq\left|x-\frac{y}{8}\right|+|x|+|y| \\
& \leq\left|x-\frac{y}{8}\right|+|x|+\left|y-\frac{x}{8}\right|+|y|
\end{aligned}
$$

dan

$$
\begin{aligned}
|x| & \leq|x|+|x-y| \\
& =|x-y|+|x|
\end{aligned}
$$

Oleh karena itu berdasarkan (31) dan (32), maka (30) menjadi:

$$
\begin{aligned}
d(f(x), f(y)) & \leq \frac{1}{8}\left(\left(\left|x-\frac{y}{8}\right|+|x|\right)+\left(\left|y-\frac{x}{8}\right|+|y|\right)\right)+\frac{1}{8}(|x-y|+|x|) \\
& =\frac{1}{8}\left(d\left(x, \frac{y}{8}\right)+d\left(y, \frac{x}{8}\right)\right)+\frac{1}{8} d(x, y) \\
& =\frac{1}{8}(d(x, f(y))+d(y, f(x)))+\frac{1}{8} d(x, y) \\
& =\frac{1}{8} d(x, f(y))+\frac{1}{8} d(y, f(x))++\frac{1}{8} d(x, y)
\end{aligned}
$$

Berdasarkan (33) jelas bahwa pemetaan $f$ memenuhi kondisi (21) dengan $\alpha, \beta, \gamma=\frac{1}{8}$, oleh karena itu berdasarkan Teorema 3.1.2 maka pemetaan $f$ mempunyai titik tetap tunggal. Lebih lanjut, titik tetap pada pemetaan $f$ adalah 0 , sebab $f(0)=\frac{0}{8}=0$, dan bersifat tunggal.

\section{Kesimpulan}

Berdasarkan pembahasan pada bab sebelumnya, maka dapat disimpulkan bahwa setiap ruang metrik merupakan ruang quasi metrik terasing, namun tidak berlaku sebaliknya. Sifat ketunggalan limit barisan di ruang metrik berlaku pula di ruang quasi metrik terasing. Tidak semua sifat barisan yang berlaku di ruang metrik berlaku di ruang quasi metrik terasing, hal tersebut berdasarkan hubungan antara ruang metrik dengan ruang quasi metrik terasing. Pemetaan $f$ yang memenuhi kondisi (16) dan (17), serta terdefinisi pada ruang quasi metrik terasing lengkap $(X, d)$ mempunyai titik tetap yang tunggal. Dalam membuktikan teorema tersebut menggabaikan sifat kekontinuan fungsi, dan memanfaatkan sifat kelengkapan pada ruang quasi metrik terasing. 


\section{Referensi}

[1] Bartle, R.G. and Sherbert, D.R. 2010. Introduction to Real Analysis. Fourth Edition. New York: John Wiley \& Sons, Inc.

[2] Dass, Bal Khishan and Gupta, Satya. An Extension of Banach Contraction Principle Through Rational Expression. F. C. Auluck, F.N.A. (1973) 1455-1458.

[3] Khamsi, Mohammad A. and Krik, William A. 2001. An Introduction to Metric Spaces and Fixed Point Theory. New York: John Wiley \& Sons, Inc.

[4] Sharma, Rajinder and Thakur, Deepti. Fixed Point Theorems without Continuity of any Mapping in Dislocated Quasi Metric Space. Int. Journal of Math. Analysis (2013) 59-64.

[5] Shirali, Satish and Vasudeva, Harkrishan L. 2006. Metric Spaces. London: Springer-Verlag.

[6] Siddiqi, Abul Hasan. 2004. Applied Functional Analysis: Numerical Methods, Wavelet Method, and Image Processing. New York: Marcel Dekker, Inc.

[7] Zeyada, F.M., Hassan, G.H., and Ahmed, M.A. A Generalization of A Fixed Point Theorem Due to Hizler and Seda in Dislocated Quasi Metric Spaces. The Arabian Journal for Science and Engineering (2006) 111114. 